NBER WORKING PAPER SERIES

\title{
VALUING INCREMENTAL HIGHWAY CAPACITY IN A NETWORK
}

\author{
H. Allen Klaiber \\ V. Kerry Smith \\ Working Paper 15989 \\ http://www.nber.org/papers/w15989
}

\section{NATIONAL BUREAU OF ECONOMIC RESEARCH \\ 1050 Massachusetts Avenue \\ Cambridge, MA 02138}

May 2010

The first author's research was completed while he was a Post-doctoral Fellow at ASU. Thanks are due Michael Kaminsky for excellent research assistance, to Mike Keane for suggesting a direct approach for implementing our two step estimator, and to Natalie Cardita and Jon Valentine for assistance in preparing this manuscript. Partial support for the research was provided by ASU's Decision Center for a Desert City. The views expressed herein are those of the authors and do not necessarily reflect the views of the National Bureau of Economic Research.

NBER working papers are circulated for discussion and comment purposes. They have not been peerreviewed or been subject to the review by the NBER Board of Directors that accompanies official NBER publications.

(C) 2010 by H. Allen Klaiber and V. Kerry Smith. All rights reserved. Short sections of text, not to exceed two paragraphs, may be quoted without explicit permission provided that full credit, including (C) notice, is given to the source. 
Valuing Incremental Highway Capacity in a Network

H. Allen Klaiber and V. Kerry Smith

NBER Working Paper No. 15989

May 2010

JEL No. H4,R14,R40

\begin{abstract}
$\underline{\text { ABSTRACT }}$
The importance of increments to an existing highway system depends upon their contributions to the accessibility provided by the existing network. Nearly 40 years ago, Mohring [1965] suggested this logic for planning optimal highway investment programs. He argued it could be implemented by measuring the quasi-rents generated by specific additions to an existing roadway system. This paper uses a unique set of additions to a loop roadway in metropolitan Phoenix, together with detailed records of housing sales over the past decade, to meet this need. We find that estimated increases in capitalized housing values due to four segments added during this period range from 73 to over 273 million dollars per mile of the roadway addition.
\end{abstract}

\author{
H. Allen Klaiber \\ Department of Agricultural Economics \\ and Rural Sociology \\ 208A Armsby Buliding \\ Pennsylvainia State University \\ University Park, PA 16802 \\ aklaiber@psu.edu \\ V. Kerry Smith \\ Department of Economics \\ W.P. Carey School of Business \\ P.O. Box 873806 \\ Arizona State University \\ Tempe, AZ 85287-3806 \\ and NBER \\ kerry.smith@asu.edu
}




\section{Valuing Incremental Highway Capacity in a Network}

\section{Introduction}

A highway is a network whose economic value depends on its inter-linked connections. Some links have greater value than others. While this judgment seems like common sense, to our knowledge no one has measured how specific roadway segments contribute to a highway network. This task is especially relevant for recent policy debates about failing infrastructure and how to prioritize spending. One third of the eighty one billion in spending on infrastructure in the stimulus package under the American Recovery and Reinvestment Act of 2009 is for highway and bridge projects. Yet, there has been little guidance offered on how to select among competing projects, aside from the criterion of being ready to start quickly. ${ }^{1}$

In October of 1985 Maricopa County voters approved a one half cent sales tax for twenty years for construction of controlled access highways. Eligibility for the funds requires that the facilities be part of the county's Regional Transportation Plan and a component of the State Highway System. Proposition 400 approved by county voters in 2004 extends the sales tax for another twenty years to 2025. These tax resources are for projects that involve new freeways, widening of existing freeways, and for bus and high speed rail. A current example of one of these projects is a proposed new segment of the loop roadway around metropolitan Phoenix -- the South Mountain Freeway. The Arizona

\footnotetext{
${ }^{1}$ A recent article in the New York Times suggests policies favoring new highways over repair as well as a willingness on the part of state officials to divert transportation funds for other projects have contributed to the poor conditions for roadways in New York, Connecticut, and New Jersey. The assessment indicates setting priorities among the maintenance and upgrade needs for the 84,000 miles of roads in this area has been difficult. See Kocieniewski [2009].
} 
Department of Transportation recently recommended scaling back the project with the planned right of way reduced from ten to eight lanes and a change in route based on budget shortfalls. Three alternatives are listed for the North-South segment completing the loop. The original objective of the funding initiative was to improve the roadway network in the metropolitan area, enhancing overall accessibility. Yet in discussing these alternatives the costs and community impacts were the primary reasons identified in describing the changes. All alternatives are implicitly considered equivalent in their contribution to the network. Figure 1 displays the proposed route alternatives. As the map displays there are differences in the potential effects of these alternatives on the areas that are readily linked to the loop network. Our analysis for completed segments suggests that these types of differences can be important to the value of connector roadways.

Few lay observers would have difficulty with this conclusion. Nonetheless when there are public or professional comments on these types of changes it has not been possible to offer more than an informal question -how does this affect overall performance of the system? Recently Greenstone [2009] has argued that our current system for evaluating regulations is "broken". He suggests that:

"It is largely based on faith, rather than evidence. The efficacy of many regulations is never assessed. Many others are only evaluated before they are implemented - the point when we know the least about them.” (pp. 111-112)

He calls for a culture of persistent experimentation and evaluation. In the context of public investment policies his suggestion was first made and illustrated by Haveman 
[1972]. Indeed his ex post assessment of water resource investments confirmed Greenstone's intuition, concluding that:

“...this study has demonstrated a need to seriously reappraise the procedures of benefit cost analysis as practiced by agencies. Unless procedures are constantly revised on the basis of performance feedback from existing undertakings, the credibility of ex ante analysis will, and should, be challenged." (p. 111)

This research was developed to respond to these calls current (and early) for ex post assessment. While we don't know that there was formal benefit-cost analysis of the roadway segments we evaluate, it is nonetheless possible to develop an ex post evaluation of their effects and to suggest how it can be used to enhance future ex ante assessments of projects similar to our example of the South Mountain Freeway.

One of the early leaders in transportation economics, Herbert Mohring [1965], provides a conceptual basis for using ex ante analysis in setting priorities. He suggested that segment specific measures of the quasi rents associated with additions to capacity were needed as part of the design and evaluation of policies to maximize the benefits from a highway network. He argued that pricing and investment decisions should take into account the differential economic importance of the links in highways as a part of networks. Much of the literature since that time has grappled with the congestion pricing component of his two decision criteria (see Parry [2009] or an overview). However, his recommendation to add capacity based on the incremental value of such investments has not. The only research that is close to meeting this challenge is an early effort by Keeler 
and Small [1977] that used engineering estimates of the relationship between speed and highway capacity in reducing congestion. It was primarily intended to estimate ex ante tolls assuming optimal capacity. Their analysis did not consider the quasi rents for specific highway segments, evaluating instead the effect of measures of capacity and tolls on congestion for different roadways in the San Francisco Bay Area.

A hedonic property value model might seem a natural possibility for implementing Mohring's proposal, especially in situations where one can observe housing prices before and after a new road segment is introduced. However, the dual challenges of selecting a proxy measure for how a highway segment influences land values and uncovering an instrument that convincingly identifies the change in property value due to each new segment have proved difficult. Even if these tasks are addressed successfully, there remains a concern about the economic interpretations of what is measured. ${ }^{2}$ Thus, it should not be surprising to find that this literature is so incomplete.

Fortunately circumstances in Phoenix, Arizona offer an opportunity to exploit the pattern of residential development in relation to new highway segments to address all three concerns. We use four new highway segments developed between 2000 and 2007 to estimate the effect of freeway additions as separate treatments influencing residential housing values. We estimate subdivision fixed effects to control for unobservable attributes of neighborhoods and of the households that select them. Within a Tiebout framework, we expect households with similar preferences for neighborhood features to sort into similar subdivisions. Under the assumption that the distribution of these unobservables in a subdivision does not change over the relatively short time periods spanned by each of the intervals associated with the highway additions in our analysis, a

${ }^{2}$ See Kuminoff and Pope [2010] and Klaiber and Smith [2009] for further discussion. 
two step regression model can be used to estimate the treatment effect of highway additions. Our application matches the conditions discussed in Starrett's [1981] classic analysis of land markets for full internal capitalization of projects yielding local public goods. By using a set of hedonic models, each estimating fixed effects for highway segments in each time period, we are able to: estimate the relative value of each new highway link; control for unobserved land uses affecting private homes at the subdivision level; and use a feasible GLS estimator to take account of the covariance structures for the estimated fixed effects in each time period.

Section two develops the context for interpreting estimates of the residential land capitalization of new highway segments as measures of the incremental benefits generated by additions to a local highway network. Section three summarizes the key elements of our estimating model. It also describes the data used in measuring the segment specific capitalization effects. Section four presents the findings and discusses their role in contributing to metropolitan Phoenix's loop road system. In the last section we consider two issues. The first concerns whether our method is unique to Phoenix due to the specialized nature of these roadway projects in relation to the residential development in the area. Second, we discuss the next steps in using roadway and residential data similar to Phoenix to develop measures of the ex ante benefits of alternative roadway projects such as would be associated with the South Mountain project.

\section{Land Capitalization and Highway Quasi-Rents}

\section{A. Background}


The use of housing prices to estimate the marginal willingness to pay for changes in spatial amenities has a long history. ${ }^{3}$ Four strategies are currently used to address these issues. Each has a mix of data requirements and maintained assumptions. The first approach is the traditional one using a single cross section of housing sales to estimate a hedonic price function. In the absence of additional information, this strategy is often criticized because the information available is regarded as incomplete. An equilibrium reflects households sorting among locations for some of the reasons that analysts can measure and due to factors that may not be readily observable. These two sets of influences (i.e. the observed and unobserved factors impacting the equilibrium) may well be interrelated. The result is a reasonable prospect for biased estimates of the effects that we seek to measure. This result follows because the factors that cannot be measured and are omitted are also often correlated with those that can be observed.

A second, reduced form, approach also uses housing prices but relies on external events and spatial fixed effects to resolve the dual challenges of unobservables and identification. The external change must be related to the amenity of interest and serves to identify its effect. ${ }^{4}$ It relies on convincing arguments and extensive documentation that the external event plays the hypothesized role (see Angrist and Pischke [2010] for arguments for this approach and its impact). The third approach proposed by Bajari and Benkard [2005] substitutes structural information for the external event. In their scheme a structural representation of the choice process allows point estimates to be derived for the marginal rate of substitution for the attribute of interest relative to the numeraire good. As Bishop and Timmins [2008] note, this approach yields point estimates of the relevant

\footnotetext{
${ }^{3}$ See Palmquist [2005] for a review.

${ }^{4}$ See Davis [2003], Chay and Greenstone [2005] and Pope [2009] as examples.
} 
marginal rate of substitution (MRS) conditional on the assumed preference function and the way each application introduces preference heterogeneity. In the simplest cases each tradeoff rate is assumed to be fixed for each household. It can vary across households but does not vary with the amount of the attribute. As a result, the Bajari and Benkard logic must impose restrictions on the hedonic price function to avoid inconsistencies in the households' implied choices and the conditions for constrained utility maximization. ${ }^{5}$

The fourth set of methods involves full structural models using either a vertical or horizontal specification for preferences (see Klaiber and Smith [2009] for a review). This approach does not escape the need for instruments. ${ }^{6}$ Nonetheless, there is a set of maintained assumptions required by these structural models as well.

Thus, the four methods yield different types of information and impose different assumptions that are unlikely to be testable within a single application. We would like to be able to interpret these differences in prices in relationship to the tradeoffs people would make to acquire the spatial (or temporal) difference hypothesized to lead to the price change.

Kuminoff and Pope [2010] demonstrate that developing an economic interpretation for estimates of capitalization is not straight forward. Extending models by Tinbergen [1956] and Epple [1987], they find that the size of the change in the spatial attribute and the heterogeneity in both the supply of alternatives as well as in the household preferences, are all important to the interpretation of capitalized price changes measured in response to exogenous events. Moreover, their empirical examples reinforce

\footnotetext{
${ }^{5}$ Kuminoff [2009] has demonstrated how the selection of a preference function and a specific distribution for the parameters associated with unobserved heterogeneity are used to augment the information we can recover from households' locational choices in identifying the parameters estimated in sorting models.

${ }^{6}$ Often the features of the equilibrium and assumptions about sorting suggest possible candidates.
} 
the importance of these general conclusions. In related work Klaiber and Smith [2009] used the assignment framework exploited by Cropper, Deck, and McConnell [1988] in evaluating specification issues with hedonic models. Their focus was on assessing the relationship between measures for housing price capitalization and the "true" general equilibrium (GE) willingness to pay. They found the spatial extent of the market for those affected by changes in spatial amenities was important to the discrepancy between hedonic estimates of the capitalization of exogenous changes in land use and GE willingness to pay.

In the current analysis the empirical model exploits a combination of spatial controls, using subdivision level fixed effects, and temporal controls based on the exogenous events associated with the completion dates for each specific highway segment. Both sources of information allow us to identify the effects of each new highway segment on land values as measured thru shifts in subdivision fixed effects. Given we can accept the assumptions of Starrett's internal capitalization model these price differentials can be interpreted as estimates of the average household's willingness to pay for each new highways segment.

\section{B. What Does Capitalization Measure for Roadway Segments?}

Starrett [1981] identified two types of capitalization as conceptual extremes. External capitalization derives from forces between communities. Internal capitalization is associated with forces inside communities. Internal is the most relevant concept for local public goods where proximity to the public good matters. Starrett used highways as one of his examples of local public goods relevant to internal capitalization. We can 
adapt his basic conceptual framework to explain how residential housing capitalization captures the economic value of increments to highway capacity. Our model begins at the household level. Each household is assumed to have a preference function, $U^{i}($.$) , that$ includes a measure of the public good associated with the highway system, $q$, and a measure of that household's use of the system, $g$, along with the amount of land, $l$, and a numeraire good, $x$. The location of links to the network will affect the cost of a trip and the value of $q$.

The household decision process envisions a conditional choice of $g$ and $l$ (land) given a selection of each location from a discrete set of alternatives. We label these potential locational choices as neighborhoods. In our empirical application we implement the model by defining a neighborhood to be a subdivision. Maximizing equation (1) for each location (where the budget constraint is substituted into the function for the numeraire, $x$ ) defines a conditional indirect utility function, $v_{\mathrm{s}}($.$) for each neighborhood$ $(s)$.

$\operatorname{Max} U^{i}\left(q, g, l, m^{i}-T^{i}-f(g, s)-r_{s} l\right.$

where:

$\mathrm{m}^{i}=$ household income $\left(x=m^{i}-T^{i}-f(g, s)-r_{s} l\right)$

$T^{i}=$ a head tax on each household

$f()=$. cost of highway use (assumed the same for all households and a function of

location)

$\mathrm{r}_{\mathrm{s}}=$ rental price of land in location $s$ 
There will be no internal capitalization if the conditional indirect utility function derived from this choice problem, $v_{s}^{i}$, is independent of the neighborhood. There must be a spatial distinction before and after each project that adds to the highway system for a welfare interpretation of price capitalization using this model. Following Starrett and assuming preferences are quasi linear in the numeraire and additively separable with $q$ and $g$ entering one component, land another, the envelop condition can be used to define cases that preclude internal capitalization. These situations arise when the expression defined in equation (2) is independent of $s$. We start by identifying this case as an extreme. It helps to explain situations where the equilibrium admits capitalization. When the indirect utility function is independent of the neighborhood, then there is no scope for the rent to adjust to q. There is no spatial differentiation across neighborhoods and the effects of a change in the public good are independent of the neighborhood selected. When rents do differ by neighborhood, they change with q, equation (2) describes the tradeoffs households in each neighborhood would make in equilibrium ( $s$ and $m$ are neighborhoods in equation (2)). ${ }^{7}$

$\frac{d}{d q} v_{s}^{i}=\frac{d}{d q} U^{i}\left(q, g_{s}\right)-l_{s} \frac{d r_{s}}{d q}=\frac{d}{d q} v_{m}^{i}=\frac{d}{d q} U^{i}\left(q, g_{m}\right)-l_{m} \frac{d r_{m}}{d q}$, for $s \neq m$

\section{As Starrett explains}

“There are two principal assumptions which taken together guarantee project benefits will be translated to land rents through the intensive margin. The first is

\footnotetext{
7 There appears to be a type setting error in Starrett's equation (2). The second term should be $-l_{s} \frac{d r_{s}}{d q}$ based on the preceding text.
} 
that all the benefits of the project must be 'intramarginal' in that boundary residents are marginally unaffected. ...The second necessary assumption is that residents do not tend to sort themselves out within the town according to their relative preference for the public good." (pp 313-314), emphasis added.

The first assumption amounts to saying we can identify a control community where the public good has no effect on the residents. He refers to these as boundary communities. The second refers to an absence of within community preference heterogeneity in tastes for public goods. ${ }^{8}$

In this setting Starrett first proposes considering the change in land rents for the boundary community in response to a change in $q$ to measure a project's benefits. With the assumption that land in the community is owned by local residents (as opposed to rented), the analysis must consider the effects of increases in demand for land across all neighborhoods and adjust for the effects of that change in recovering the differential change due to $q$ for the neighborhoods assumed to be impacted. These are the treated subdivisions in our empirical model.

We can adapt equation (2) using the definition of the boundary community (labeled with the subscript $\sigma$ ), together with the household sorting that leads to equalization of the net contribution to utility and defines equilibrium adjustments due to a change in $q$.

\footnotetext{
${ }^{8}$ In contrast, structural sorting models permit diversity in preferences within a community because it is recovered as a maintained distributional assumption. The specific form of the joint distribution of income and tastes is used, along with the properties of the equilibrium to identify the parameters describing the heterogeneity.
} 
$\frac{d}{d q} U^{i}\left(q, g_{s}\right)-l_{s} \frac{d r_{s}}{d q}=\frac{d}{d q} U^{i}\left(q, g_{\sigma}\right)-l_{\sigma} \frac{d r_{\sigma}}{d q}$

The first term on the right side of equation (3) is zero because $\sigma$ is a boundary

community. The second term $\left(l_{\sigma} \frac{d r_{\sigma}}{d q}\right)$ will depend on whether the project affects the overall demand for land. If it does, then we have the general form of a difference in difference model in equation (4).

$l_{s} \frac{d r_{s}}{d q} l_{\sigma}-l_{\sigma} \frac{d r_{\sigma}}{d q}=\frac{d}{d q} U^{i}\left(q, g_{s}\right)$

The left side of this expression describes the difference in the change in land prices due to project for the affected community (s) compared to the change in land prices due to the overall demand changes (and other factors potentially) induced indirectly by the project for the boundary (or control) community $(\sigma)$, where we assume households experience no gain due to the change in q. This formulation clearly displays that two differences are needed. The project's impact (and the change in q due to it) for the communities that experience the gain and the indirect effects on controls that do not experience gains (due to area wide changes in the demand for land).

If we further expand the model and allow for preference heterogeneity within communities (a situation that was assumed away in the basic development), Starrett argues that land rents will tend to undercapitalize the benefits of a change in q. This result follows, in part, from a stability condition for the town structure. For our purposes, we must assume that households are homogeneous within each neighborhood. To do 
otherwise, as we discuss at the close of the paper, requires a structural model with maintained assumptions characterizing household heterogeneity. Our estimates for the effect of the additions to the highway network assume that the roadway effects can take two forms. In our basic model the effect is constant for each neighborhood. In the second specification the effect varies based on the inverse distance to the highway segment. For the remaining terms in the model, Starrett's separability assumptions assure that there is no adjustment in response to changes in $\mathrm{q}$.

The effects of roadways in our application are not continuous. They are assumed to be capitalized at the subdivision level. The ability to distinguish these subdivisions from assessor records is important to our strategy for identifying the incremental willingness to pay for enhanced accessibility. In Phoenix the homes in each of the subdivisions have lot sizes that are approximately equal. This feature implies that once households select a neighborhood, sorting assures they will have comparable demands for lot size as well as all the other attributes conveyed by that subdivision. We assumed in our model that households' costs of using the roadway, as represented by $f($.), were the same.

As we noted the measure in (4) requires two things: (1) home sales and the identification of their locations in subdivisions and (2) a change in accessibility due to changes in highway segments (i.e. the $d q$ ). Without this change in roadway segments we don't have a difference in accessibility that can be distinguished from the subdivision fixed effect. We have instead the equivalent of what Starrett intends to be measured with $\left(l_{s} r_{s}-l_{\sigma} r_{\sigma}\right)$ given the lot size features of subdivisions in Phoenix. In his framework the other features of houses (and lots) are held constant. The only reason for land rents to 
differ across neighborhoods (or in our case subdivisions) is due to differences in the amount of $q$ available to households who live in each. To measure the effects of changes in $q$ we need some basis for measuring how $r_{s}$ and $r_{\sigma}$ change with $q$. Thus, adding the ability to observe these subdivision effects over time with the completion of new roadway segments provides this opportunity. (i.e. measuring $l_{s} \frac{d r_{s}}{d q}-l_{\sigma} \frac{d r_{\sigma}}{d q}$ ).

We can measure these changes by having access to information on housing sales before and after each highway segment's completion and opening. Thus, a difference in these fixed effects with each opening or, equivalently, a difference in differences approximates the left side of equation (4). Sorting assures all other contributions that would distinguish partial and general equilibrium effects are at the ex post equilibrium values. If we assume an algebraic relationship between the proximity of a subdivision to completed roadways, then our strategy of using subdivision fixed effects over time together with this measure can be interpreted as a variant of the Athey and Imbens[2006] change in changes approach to measuring the effects of the treatment.

Overall, then, our empirical model tests the internal capitalization condition directly. The subdivision fixed effects measure the contribution to the housing prices in a neighborhood as a result of each house's location in that area. These effects account for the unobserved factors that distinguish home prices in a particular neighborhood from all others, after controlling for house attributes, the lot size, and other observables. If measures of highway segments fail to be significantly related to the subdivision effects' changes over time, then we conclude that there was no new internal capitalization.

Of course, one might argue that roadways are planned long in advance and, once the path is known, the value of accessibility should already be capitalized into the 
subdivision fixed effects. Certainly it is true that roadways require significant lead time. However, the anticipated effects measure ex ante beliefs that cannot be recovered using subdivision fixed effects without additional information. We seek to estimate what people believe they would be obtaining. ${ }^{9}$ Diversity in beliefs would not necessarily be reconciled thru sorting, though it is reasonable to expect those with the strongest preferences for access would move first. These expectations should make it more difficult for us to estimate the ex post general equilibrium effect. If households perfectly anticipated the gains (there were no unanticipated general equilibrium effects due to access), then there should not be a significant change in subdivision fixed effects for the treatment group (those with increased accessibility due to the new roadway) compared to the change in those for the control neighborhoods between the time spans involved.

As we noted earlier, internal capitalization also requires that the benefits are "intra-marginal." Starrett explains that in cases like ours this condition means that some neighborhoods realize no gains from increments to the local public good. In our case it translates into an assumption that not all subdivisions within the overall area benefit from each new highway segment. This assumption means that we need to define a set of subdivisions that serve as controls in both spatial and temporal terms. In practice this requirement implies we assume that at some distance from a new segment the roadway's role in creating increased access to the network has no value. This condition is consistent with the features of a loop roadway that provides a highway network within a metropolitan area but is not enhancing connections to outside metropolitan areas. The highway segments we selected were (from the planning descriptions) intended to serve

\footnotetext{
${ }_{9}^{9}$ Indeed Poulos and Smith [2008] in a different context use this logic to define information treatment that estimates the ex ante negative effect of a highway.
} 
metropolitan Phoenix, but do not change the area's accessibility to other more distant population centers. We assume the added segments have primarily a local value and will be important to subdivisions near it. To meet this condition we impose a three mile threshold for effects as a maintained hypothesis for our second step estimates. ${ }^{10}$

When these conditions are satisfied the incremental benefits of additions to a public good are measured by residential land capitalization. These increments could be used to estimate the net quasi-rents due to the project. Starrett's proof of this result makes strong assumptions about preferences and assumes the lump sum taxes imposed on households cover the incremental costs of the increases to public goods and that household income includes profit shares, rental income on land, and labor earnings, with the latter unaffected by increments to $q .{ }^{11}$

While these are important maintained assumptions in his general capitalization result, our strategy uses them as a starting point for interpreting the empirical results. We do not argue that our findings offer measures of the aggregate quasi-rents for highway segments. Instead we suggest they offer a basis for ranking the segments and discuss in the closing section some strategies for extending the analysis for ex ante assessment of these aggregate quasi rents.

\section{Empirical Model and Data}

\section{A. Empirical Model}

\footnotetext{
${ }^{10}$ We investigated the sensitivity of our results to alternative specifications of this threshold and the basic conclusions are maintained. In particular, we examined a 5 mile cutoff and found that magnitudes of parameters decreased, but signs and significance were maintained.

${ }^{11}$ There are differences in property tax rates across some of the municipalities and school districts within our study area, Maricopa County, but these will also be controlled with our subdivision fixed effects. Moreover, the roadways are paid thru county wide sales taxes not property taxes directly associated with the roadways
} 
Our analysis uses on a two step hedonic property value model. Separate first-stage models are estimated for housing sales in each of five periods - a control time span before the new roadways are completed and four other periods with time spans defined by the sequential dates for the opening of each of the four highway segments. Our sample includes all subdivisions with at least 13 sales per time period. Each model includes a full set of variables describing the homes' characteristics and the attributes conveyed by location as well as fixed effects identifying the subdivisions in each time span. Equation (5) specifies the general form for the first-stage hedonic model specification, a semi-log equation. It maintains that the housing sales price, $\left(P_{i}\right)$ is a function of housing and lot characteristics, a monthly time index, and subdivision fixed effects.

$\ln P_{i}=\alpha_{0}+\sum_{j} \beta_{j} c_{j i}+\sum_{k} \gamma_{k t} s_{k i}+\theta M_{t}+\epsilon_{i}$

where:

$t=$ identifies the time periods for each sample

$c_{j i}=$ designates housing and lot characteristics

$s_{k i}=$ corresponds to subdivision fixed effects

$M_{t}=$ monthly time trend

$\varepsilon_{i}=$ unobserved error

The second step "stacks" the five sets of estimates for the subdivision fixed effects in a single sample to allow these effects to be used to estimate the effects of two different characterizations of roadway effects on the homes in each subdivision. The model is an unbalanced panel with different subdivisions affected by the highway segments in each 
time interval. ${ }^{12}$ When subdivisions appear in repeated sub-samples over time the qualitative terms for highway segments are coded so that they influence land values (thru the subdivision fixed effects) from the point of completion of the roadway until the end of the sample period. Equation (6) specifies the estimated subdivision fixed effects to be a function of an indicator variable that identifies subdivisions that satisfy two conditions. They are within three miles of each new roadway segment and the sales were after that highway segment opened. The model also includes a fixed effect to capture noise and disamenity attributed to subdivisions within 1,500 feet of a highway segment. This effect is interacted with the timing fixed effect. Finally a measure of distance to the central business district is included.

We consider the proximity to each highway segment in two different formats: (a) the primary model is a fixed effect for the subdivisions within three miles of the roadway segment (this corresponds to what we labeled earlier as the difference in differences effect); and (b) the second uses the inverse distance to the roadway truncated to zero at 3 miles (this approach is a variation on the Athey and Imbens change in changes model). This formulation gauges the sensitivity of our findings to treating the highway effect as fixed. ${ }^{13}$ After each roadway opens these variables (and the fixed effects identifying subdivisions adjacent to each segment) are assumed to continue to exert an influence on the subdivisions' contribution to housing sales prices.

\footnotetext{
${ }^{12}$ In addition to different segments, it is possible that we might not observe a minimum of 13 sales within a subdivision for some time periods. Either outcome would remove a subdivision from the housing sales included in the first step model and thus the corresponding subdivision fixed effect for the time period in which this occurs.

${ }^{13}$ As noted in footnote \#10 we also tested using a greater distance threshold and found comparable effects to those reported here.
} 
$\hat{\gamma}_{k t}=a+\sum_{l=1}^{4} b_{l} d_{l k} D_{l k t}+\sum_{l=1}^{4} e_{l} A_{l k t} D_{l k t}+c d_{C B D k}+u_{k}$

$d_{l k}=$ corresponds to either the dummy variable for the distance interval (or the inverse distance of road segment $l$ from subdivision $k$ for the robustness check)

$D_{l k t}=1$ if the road segment was opened in the time period defining interval $t$ or in a previous time period

$=0$ otherwise

$A_{l k t}=1$ if the subdivision was adjacent to a completed highway segment during the period

$=0$ otherwise

$d_{C B D k}=$ distance of subdivision $k$ to the central business district.

Our two step strategy requires that we have estimates of both the fixed effects and their covariance structure. By applying a Cholesky decomposition to each estimated covariance structure for the fixed effects from each first stage model, the variables in equation (6) may be transformed so that the feasible generalized least squares estimator required for the second stage model can be derived using ordinary least squares with the transformed "stacked" data. ${ }^{14}$ This decomposition is especially convenient because there are over 15,000 subdivisions included in the full sample over all five sub-periods.

Equation (6) hypothesizes two types of effects for the treated subdivisions. The first assumes that once a highway opens all homes experience a constant percentage increment due to increased access to the roadway network. This effect persists thru time

\footnotetext{
${ }^{14}$ The estimated parameters are based on each sub period and transformed using the relevant Cholesky matrix for the estimated covariance structure for each sub period and then stacked. This result follows because the covariance matrix for the feasible GLS applied to the pooled set of fixed effects is assumed to be block diagonal.
} 
as subsequent segments open due to the definition of the time fixed effect $\left(D_{l r}\right)$. For subdivisions adjacent to a segment there may well be dis-amenity effects due to noise or pollution. Changes in land uses near segments such as strip malls or commercial structures could also be expected to influence these subdivision terms. The fixed effects identifying adjacent subdivisions will capture the net impact of all of these influences.

In a second specification, we consider the possibility of spillover effects between highway segments. To describe how this was implemented it is important to outline the spatial structure of the changes in the highway system and then describe how interactions between segments were hypothesized to alter the contribution of each new segment to the accessibility of each subdivision to other areas within the metropolitan area.

During this time span several major loop freeways in the Phoenix area were completed. This overall process for expanding the loop roadway involved four major segments. Figure 2 displays the segments with color coding for the Price segment (green), the Pima (blue), Santan (black) and connector (red). The southern segment of Loop 101 (Price) connecting the cities of Tempe and Chandler was completed in December 2000. The northern segment (Pima) connecting Scottsdale to Tempe was completed in April 2002. Another project linking the Loop 101 with Interstate 10, a major interstate, opened in November 2003 (connector). The second loop roadway, Loop 202, opened in June 2006 with the completion of a 12 mile segment of the Loop 202 joining the southern section of the Loop 202 Freeway linking Loop 101 and US 60 through the cities of Chandler and Gilbert (Santan).

A closer look at the segment labeled Price indicates that it is along the eastern boundary of Phoenix. It is a north-south segment linking the southern (and middle) 
residential areas to the major east-west connectors (i.e. Route 10 and 60). The Pima component completes this north-south link providing access to and from Scottsdale and provides an east-west thoroughfare connecting at the northern edge of the metro area. Our spillover hypothesis suggests that completing the Pima segment may change the value of the Price segment. A similar argument could be applied to the Price connector and Santan segments along the southern boundary providing another east-west link to Interstate Route 10. These effects are tested by introducing different sets of interactions of the separate fixed effects for each roadway segment.

\section{B. Data and First Stage Results}

Our application involves over 600,000 sales of private homes in Maricopa County from January 1, 1999 to June 30, 2007. Table 1 identifies the time period corresponding to each completed segment, the number of subdivisions that had sales affected by each highway segment, as well as the control time period. Table 2 provides two sets of summary statistics. The top panel describes the characteristics of the properties involved in housing sales. This includes the mean, standard deviation, the minimum, and the maximum values for price and variables describing the characteristics of each house. In addition it includes the distance between the centroid for each house and the roadway segments. The bottom panel describes the features of the subdivisions included in our sample. It reports the average number as well as the size of the smallest and largest subdivision and the years they were built.

Table 3 provides estimates of the hedonic price equations for each time period. The values in bold designate the estimated parameters that were significantly different 
from zero with p-values of 0.10 or less. Following many previous hedonic studies, our specification includes quadratic effects for age, lot size, and house size. Overall, the effects of housing attributes were quite stable over the eight years comprising our sample period and generally agree with our expectations for the effects of each of these structural variables. The relative stability of the estimated parameters over time suggests that these coefficients reflect the construction costs during the period. Locational effects of where houses are placed are captured by the subdivision fixed effects. We do not report specific estimates for the fixed effects for the subdivisions estimated separately for each time period.

We selected two roadway segments-Price and Pima and developed kernel density estimates for the fixed effects (using the three mile threshold) to identify treated and control subdivisions in each time period. Figure 3 displays the results for the first roadway segment to be completed, the Price, and Figure 4 is the Pima segment. In each figure we display the density estimated for the treated (blue) and control (red) subdivision fixed effects by sub-period and for the overall sample. The effects of each roadway on the values of the affected subdivisions are clearest using the sub-period plots. For the Price in sub-periods 3,4 , and 5 there is a clear displacement of the treated subdivisions to yield larger estimated changes in the fixed effects than the control compared to the base time period. This is the distinction that our second stage model isolates for each roadway segment. The second stage model acknowledges that the fixed effects are not independently estimated and takes account of these correlations with the feasible generalized least squares estimator. These sample kernel density estimates assume 
independence. Nonetheless these simple graphs are useful in providing a general idea of what the second stage models are capturing.

The Pima kernel estimates display the shift in fixed effects for this roadway segment as well. There is no period two in this case because the first time period after this roadway was completed is our period three. All three periods for the Pima display a shift and the full time period (in the last panel) more clearly displays the treatment effect. As we discuss in the next section, the connector and the Santan segments do not have as large an influence as the Pima and Price. As a result, we do not report kernel density estimates for them.

Figures $5 \mathrm{a}$ thru $5 \mathrm{~d}$ display the clustering of the subdivisions that are serving as the treated cases for each highway segment (in red) and the controls (in black). As the figures confirm there is a clear delineation of the treatments used for each segment.

\section{Estimates of the Incremental Values for New Highway Segments}

Table 4 presents five different specifications of the second stage model. The first panel is the simplest model with the fixed effect terms for each roadway, including whether the subdivision is within three miles of roadway segment and the time period for the hedonic model was after the completion of the segment. This simplest specification also identifies whether a subdivision was adjacent to the segment and includes the distance to the Central Business District (CBD). The second panel includes these variables along with interaction effects to consider spillover effects that are associated with directional spillovers. The third panel focuses on spillovers that focus on connection effects between new and existing roadway segments. The fourth includes all fixed effects 
and interaction variables. The last is a robustness check replacing the fixed effects with the inverse distance between subdivisions and relevant roadway segments.

Our primary focus is on the estimates treating the highway as a fixed effect with an implied constant mean effect (in percentage terms) for the subdivisions impacted by each new highway segment. Regardless of whether the fixed effect (the first panel) or the inverse distance (fifth panel) is used, there is a clear ranking of the contributions of different highway segments to housing prices, with the north / south Pima segment the most important, increasing housing prices by about twenty four percent. The Price/10 connector has the second largest impact that is significant and stable, indicating a thirteen percent increase in housing prices for homes in a subdivision near this segment after it was completed. The remaining segments also have significant effects on the subdivision's contributions to prices with a mean effect of seven percent for the Santan segment and about four percent for the Price segment.

The models considering spillover effects are defined using interaction terms under a "directional" or "connection" based rationale. These interactions are only significant when they involve the Price segments. They do not appear to alter the overall effect for composites of the completed roadway segment, suggesting that the simpler formulation offers the best description of the highway segments' effects. That is, assuming separate fixed effects offers the best guide to the relative importance of each highway component. The fixed effects for adjacent impacts are only statistically significant for the north / south Pima segment using the full fixed effects specification. This effect reflects a large set of land use changes that took place in the areas around this segment because of its enhanced accessibility. Figure 5a illustrates the location of the subdivisions along this 
segment. There has also been significant commercial development in this area that closely aligns with the roadway. The composite of these two impacts on the adjacent subdivisions is reflected in these fixed effects.

The last component of our analysis is in the fifth panel of Table 4. We estimate no spillover (i.e. interactions between segments) model replacing a fixed effect for subdivisions within each roadway segment with the inverse distance for the centroid of the subdivision in relation to the closest point of the roadway. This term is interacted with the fixed effect identifying when each segment opened (i.e. the $D_{i k t}$ in equation (6)).

Two conclusions emerge from this gauge of the sensitivity of our findings. First, as we noted at the outset of this discussion of findings, our conclusions about the ranking and statistical significance of these new roadway effects remain stable for the segments with the largest effects. Second, when we evaluate the estimates at the mean of the inverse distance for the treated subdivision in our sample, the estimated average effect is consistent but smaller compared to what we found with the models that assumed the effects were constant. Only the Santan and Price display results that switch order of importance and these would not be significant differences. More specifically, the estimates at the mean values for the inverse distance are: 12 percent for Pima, 5 percent for the connector to the Price, 2.3 percent for the Santan and 2.5 percent for the Price segment.

Our adaptation of Starrett's model suggests the difference in differences logic recovers increments that reflect the sorting response of households to each neighborhood after each change. These estimates provide the ex post increments to the willingness to pay attributable to each roadway's contribution to accessibility. At an aggregate level 
they are approximate because we are using the average proportionate change together with the average house price to estimate average increments. ${ }^{15}$ At best then, the results should be interpreted as ranking the segments. In Table 5 we report a simple approximation using the percentage increment for each roadway segment and the average of the sales prices in the affected subdivisions to provide an order of magnitude measure of these effects in comparison to the costs for each roadway segment.

As cautioned earlier these are not estimates of aggregate quasi rents. We are gauging the size of the overall effects to judge whether small percentage effects on the average subdivision for some roadway segments considered together with the number of houses in these neighborhoods would change the ranking due to the number of affected properties. In our case they would. The top ranked roadway segment remains unchanged but the ordering of the others would be affected. This finding reinforced the need to consider measuring both the average treatment effect and assessing the size of the impacted area in the design of ex post evaluations. While there are many assumptions to interpret these as benefit measures, for many purposes even the aggregate capitalized value of specific segments offers sufficient information to gauge the importance of the roadway segments.

Table 5 provides the elements that contribute to our estimate of aggregate changes to evaluate our segment ranking. The first two columns report the number of houses near each segment and those defined as adjacent to the roadway. Recall our estimates

\footnotetext{
15 i.e. if $\Delta \mathrm{q}$; is the change in accessibility due to segment $\mathrm{j}$, then the $\mathrm{WTP}^{i}$ for household $i$ would be:$$
U^{i}\left(q+\Delta q j, g^{*}, l^{*}, m^{i}-W T P^{i}-T^{i}-f\left(g^{*}, s^{*}\right)-r_{s^{*}} l^{*}\right)=
$$$$
U^{i}\left(q, \widetilde{g}, \tilde{l}, m^{i}-T^{i}-f(\widetilde{g}, \tilde{s})-r_{\tilde{s}} \tilde{l}\right)
$$

Where $*$ and $\sim$ identify the differences in the utilization and land with and without the increased accessibility implied by $\Delta q_{j}$.
} 
suggested that subdivisions near the roadway gained relative to controls but the gain was reduced somewhat if these areas had homes that were adjacent to the roadway. Hence both factors need to be considered in computing the increment to an aggregate for each highway segment. The next four columns report the number of sales and average prices for home affected by each highway segment. These are taken from the treated subdivisions. We distinguish whether they are near or adjacent to the highway. The seventh column reports our estimate for aggregate increment to evaluate our ranking based on fixed effects alone.

If we use them as an order of magnitude gauge of the importance of the roadway segments and compare them to the costs of each segment, we would conclude that all have had impacts on land values that clearly exceed their costs. ${ }^{16}$

Ideally, a full benefit cost analysis would includea more complete accounting of who gains and loses. As Mohring [1961] suggested, there are both gainers and losers across each metro area. Starrett's model assumes any income effects of capitalization will be reflected in the bids for residential properties. We suspect, due to the rapid population growth during the period of our sample's transactions, that these roadways influenced the placement of new subdivisions and thus channeled growth of residential housing. Our use of controls to capture the boundary effects takes account of some of these influences. Real housing prices in other areas probably did not decline over this period. The influx of new households may have been responsible for avoiding a relative decline in real prices for the areas that might have failed to gain access to the overall area during the period we

\footnotetext{
${ }^{16}$ Cost estimates are obtained from yearly certification reports prepared by the Arizona Department of Transportation. These reports show the progression of the freeway system as well as the costs for each segment. When possible, we use the cost associated with segments under construction rather than the estimated pre-construction costs.
} 
study. This is why Starrett's argument to consider the effects of overall land demands on the boundary community's land values is important to detecting the net effect of each highway segment. A structural model would be needed to judge how these aggregate approximations relate to the quasi-rents for these segments during this period. ${ }^{17}$

\section{Implications}

Mohring's [1965] call for greater attention to marginal cost pricing and economic principles in managing existing roadways and in evaluating increments to their capacity seems especially relevant to today's policy climate where increased infrastructure investment is viewed as especially important as a stimulus for aggregate economic activity and as a long term need for economic growth. Research considering the implementation of Mohring's proposal for evaluating highway investments has been virtually non-existent.

We argued that Starrett's capitalization results can provide an effective rational for measuring the gains (at the subdivision level) due to highway segments that generate primarily local benefits within a metropolitan network. Our example is based on key segments added to the loop roadways around metro Phoenix between 2000 and 2007. An important question is whether it is possible to exploit the results from this type of analysis to evaluate the ex ante incremental benefits from potential additions to other roadway systems.

We answer this question in two ways. First, for Metropolitan Phoenix, which recently extended the $1 / 2$ cent sales tax 20 years to fund expansion of the freeway system,

\footnotetext{
${ }^{17}$ All of these areas experienced significant price declines after the end of our sample period. There is
} no reason to believe that these effects eliminated the relative value of segments near each roadway. 
our results help provide guidance for the best types of roadways to target for additional infrastructure spending. In fact, the first roadway targeted for the expansion of HOV lanes was the Pima Freeway, consistent with our findings that this roadway is associated with the largest capitalized benefit.

In terms of using our results to inform policymakers in other areas, our results are not likely to translate directly. However, there is a link between the way Starrett posed the question of internal capitalization and the current generation of vertical sorting models (see Sieg et al [2004]) that may be worth pursuing in developing a calibrated land valuation model for this task. Starrett's neighborhood effects are similar to the effects of local public goods in the Epple-Sieg [1999] vertical sorting model. That is, in these models, the equilibrium conditions under the assumption preferences satisfy the single crossing condition imply housing prices and public goods are linked. The nature of the link depends on the preference specification. For the case of the CES function used in Sieg et.al [2004] there is a simple updating rule linking neighborhood price indexes and the neighborhood specific public goods. The relation exploits the ascending bundle property of the equilibrium. This condition assures neighborhoods will be ranked the same way if compared by housing (or land) prices or an index of public goods. Thus, the prices and public goods indexes of adjoining neighborhoods (in the sense of being ranked together) can be used to structure an updating rule for prices if the public goods change or to compute the index of local public goods if the prices are different. It is this relationship that could be used to calibrate preferences.

A sketch of the logic would proceed as follows. We would need to observe housing prices before and after a highway project to estimate price indexes for a set of 
neighborhoods comprising the choice set relevant for the market equilibrium in the area where we would like to project the benefit of the improvement. The new location's application need not have the level of experimental detail distinguishing treatment and control neighborhoods, as in the case of our Phoenix example. It would require the before and after price indexes, and measures of the neighborhoods used to get the relationship to the new roadway. Under these conditions, the estimated effects of new roadway proximity from Phoenix could be used as relative values in the new location-a calibration would attempt to use them in a public goods index to estimate the post project prices.

Klaiber and Smith [forthcoming] have found support for a vertical sorting model for Maricopa County based on local school quality using school districts as the basic choice alternatives. Augmenting it to reflect our findings here would require significant additional information and qualifying "ifs" and assumptions. Nonetheless, the basic point is that using the structural foundation of the internal capitalization model is one way to extend the results where the conditions associated with highway developments did not offer the controls offered by our example.

Even if this scheme is judged too arbitrary for most highway projects, there is scope for exploiting Starrett's internal capitalization within a DD framework. Over the past decade—rapidly growing areas like Las Vegas, Nevada, the Research Triangle area of North Carolina and suburban Atlanta, Georgia as well as other areas may well offer examples where this logic could be replicated to judge the overall viability of Mohring's proposal to rank highway projects. 


\section{References}

Angrist, Joshua and Jörn-Steffen Pischke, 2010. "The Credibility Revolution in Empirical Economics: How Better Research Design is Taking the Con Out of Economics." NBER Working Paper \#15794.

Athey, Susan and Guido W. Imbens, 2006. "Identificaiton and Inference in Nonlinear Difference in Difference Models," Econometrica, Vol. 74 (March): 431-498.

Bajari, Patrick and C. Lanier Benkard. 2005. "Demand Estimation with Heterogeneous Consumers and Unobserved Product Characteristics: A Hedonic Approach." Journal of Political Economy, 113(6): 1239-76.

Bajari, Patrick and Matthew E. Kahn, 2005. "Estimating Housing Demand with an Application to Explaining Racial Segregation in Cities." Journal of Business and Economic Statistics, 23(1): 20-33.

Bishop, Kelly and Christopher Timmins, 2008. "Simple, Consistent Estimation of the Marginal Willingness to Pay Function: Recovering Rosen's Second Stage without Instrumental Variables." Mimeo.

Chay, Kenneth Y. and Michael Greenstone, 2005. "Does Air Quality Matter? Evidence from the Housing Market." Journal of Political Economy, 113(2): 376-424.

Davis, Lucas,2004. “The Effect of Health Risk on Housing Values: Evidence from a Cancer Cluster." American Economic Review, 94(5): 1693-704.

Eberts, R.W. and McMillen, D., 1999. “Agglomeration Economics and Public Infrastructure". In P. Cheshire and E.S. Mills (eds.), Handbook of Urban and

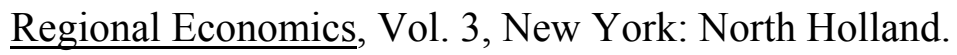


Epple, Dennis, 1987. "Hedonic Prices and Implicit Markets: Estimating Demand and Supply Functions for Differentiated Products." Journal of Political Economy, 95(1): 59-80.

Epple, Dennis and Holger Sieg, 1999. "Estimating Equilibrium Models of Local Jurisdiction." Journal of Political Economy, 107(4): 645-81.

Gramlich, Edward and Rubinfeld, Daniel, 1982. "Micro Estimates of Public Spending Demand Functions and Tests of the Tiebout and Medium Voter Hypotheses." Journal of Political Economy 90: 536-560.

Greenstone, Michael, 2009. “Toward a Culture of Persistent Regulatory Experimentation and Evaluation" in David Moss and John Cisternino, editors, New Perspective on Regulation, (Cambridge, MA: The Tobin Project).

Haveman, Robert H., 1972. The Economic Performance of Public Investments: An Ex Post Evaluation of Water Resource Investments (Baltimore: Johns Hopkins University Press for Resources for the Future).

Keeler, Theodore E. and Kenneth A Small, 1977. “Optimal Peak- Load Pricing, Investment and Service Levels on Urban Expressways" Journal of Political Economy, Vol 85 (February): 1-25.

Klaiber, H. Allen and Daniel J. Phaneuf, 2009."Valuing Open Space in a Residential Sorting Model of the Twin Cities." Journal of Environmental Economics and Management. (forthcoming).

Klaiber, H. Allen and V. Kerry Smith, 2009. "Preference Heterogeneity and Non-Market Benefits: The Roles of Structural Hedonic and Sorting Models" in Jeff Bennett, editor, The International Yearbook of Non-Market Valuation 
(Cheltenham, U.K.: Edward Elgar, forthcoming)

Klaiber, H. A. and V. Kerry Smith, 2009. "Evaluating Rubin's Causal Model for Measuring the Capitalization of Environmental Amenities." NBER Working Paper \#14957.

Kuminoff, Nicolai V., 2009. "Decomposing the Structural Identification of Nonmarket Values." Journal of Environmental Economics and Management, 57(2): 123-39.

Kuminoff, Nicolai V and Jaren C. Pope, 2009. "Capitalization and Welfare Measurement in the Quasi-Experimental Hedonic Model" mimeo.

Lind, Robert C., 1973. "Spatial Equilibrium, The Theory of Rents, and the Measurement of Benefits from Public Programs." Quarterly Journal of Economic, 87 (2): 188207.

McDonald, John and Osuji, Clifford, 1995. "The Effects of Anticipated Transportation Improvement on Residential Land Values." Regional Science and Urban Economics, 25: 261-278.

Mills, Edwin, 1967. “An Aggregate Model of Resource Allocation in a Metropolitan Area." American Economic Review 57: 197-210.

Mohring, Herbet, 1965. "Urban Highway Improvements" in Robert Dorfman, editor, Measuring Benefits of Government Investments, (Washington, D.C.: The Brookings Institution).

Mohring, Herbert, 1961. "Land Values and the Management of Highway Benefits," Journal of Political Economy, Vol. 69 (June): 236-269.

Palmquist, Raymond B., 1982. "Measuring Environmental Effects on Property Values without Hedonic Regerssions.” Journal of Urban Economics, 33 (3):333-47. 
Palmquist, Raymond B., 2005. "Property Value Models," in Handbook of Environmental Economics, Volume 2. Karl-Göran Mäler and Jeffery Vincent eds. Amsterdam: North Holland Press.

Parry, Ian, 2009. "Pricing Urban Congestion" in Annual Review of Resource Economics, edited by Gordon Rausser (Palo Alto: Annual Reviews, PP 461-484).

Pope, Jaren C., 2008. "Buyer Information and the Hedonic: The Impact of a Seller Disclosure on the Implicit Price for Airport Noise." Journal of Urban Economics, 63(2): 498-516.

Poulos, Christine and Smith, V. Kerry, 2008. "Do New Highways Create New Sources of Stigma?" Working Paper RTI International and CEESP, Arizona State Univeristy (2008).

Sieg, Holger, V. Kerry Smith, H. Spencer Banzhaf, and Randy Walsh, 2004. "Estimating the General Equilibrium Benefits of Large Changes in Spatially Delineated Public Goods." International Economic Review, 45(4): 1047-77.

Starrett, David A., 1981. “Land Value Capitalization in Local Public Finance,” Journal of Political Economy, Vol. 89 (April): 306-328.

Tiebout, Charles, 1956. “A Pure Theory of Local Expenditures,” Journal of Political Economy, Vol. 64: 416-424.

Tinbergen, Jan, 1959. "On the Theory of Income Distribution," in Selected Papers of Jan Tinbergen. L.H. Klaassen, L.M. Koych and H.J. Witteveen eds. Amsterdam: North Holland. 


\section{Table 1: Time Periods}

\begin{tabular}{cccll}
\hline Time Period & \# Sales Cutoff & \# Subdivisions & Date Range & Segment Completed \\
\hline 1 & 13 & 3,144 & January 1, 1999 to December 22, 2000 & Pre-completion \\
2 & 13 & 1,844 & December 23, 2000 to April 7, 2002 & Price \\
3 & 13 & 3,162 & April 8, 2002 to November 16, 2003 & Pima \\
4 & 13 & 6,034 & November 17, 2003 to June 11, 2006 & Price connector \\
5 & 13 & 1,555 & June 12, 2006 to Jun 30, 2007 & Santan \\
\hline
\end{tabular}


Table 2. Housing $(N=619,494)$ and Subdivision $(N=15,739)$ Summary Statistics

\begin{tabular}{lrrrr}
\hline Variable & Mean & Std Dev & Min & Max \\
\hline Price & 236850 & 265143 & 17000 & $1.00 \mathrm{E}+07$ \\
Square Feet & 1951 & 720 & 600 & 5997 \\
Acres & 0.19 & 0.13 & 0.05 & 6.790381 \\
Stories & 1.24 & 0.43 & 1 & 4 \\
Bathrooms & 2.69 & 0.81 & 0.5 & 6 \\
Age & 11.33 & 14.09 & 1 & 88 \\
Garage & 0.96 & & & \\
Pool & 0.29 & & & \\
\hline Price Distance ${ }^{\text {a }}$ & 18.15 & 9.74 & 0.01 & 63.56 \\
Pima Distance & 11.60 & 6.27 & 0.01 & 59.40 \\
Connector Distance & 20.35 & 10.29 & 0.02 & 65.87 \\
Santan Distance & 20.57 & 13.26 & 0.04 & 69.72 \\
\hline & Subdivision Statistics & & \\
\hline Size (N=10,696) & 88.56 & 83.45 & 13 & 1115 \\
Number of Sales & 39.36 & 45.82 & 13 & 855 \\
Year Built & 1988.09 & 14.90 & 1925 & 2007 \\
Age at Sale & 15.88 & 14.92 & 1 & 81 \\
Age at Sale Spread & 2.64 & 5.22 & 0 & 80.09 \\
\hline
\end{tabular}

${ }^{a}$ Distance measures are not included in first-stage hedonic (in miles). 
Table 3. First-Stage Log-Linear Hedonic Results by Time Period

\begin{tabular}{|c|c|c|c|c|c|}
\hline \multirow[b]{2}{*}{ Variable } & \multicolumn{5}{|c|}{ Time Period } \\
\hline & 1 & 2 & 3 & 4 & 5 \\
\hline Square Feet (100s) ${ }^{1}$ & 0.0437 & 0.0449 & 0.0440 & 0.0410 & 0.0415 \\
\hline Acres & 0.5296 & 0.6106 & 0.5650 & 0.4921 & 0.7211 \\
\hline Stories & -0.0396 & -0.0566 & -0.0576 & -0.0400 & -0.0480 \\
\hline Bathrooms & 0.0291 & 0.0350 & 0.0343 & 0.0250 & 0.0245 \\
\hline Age & 0.0014 & 0.0008 & -0.0039 & -0.0001 & -0.0070 \\
\hline Garage & 0.0475 & 0.0382 & 0.0463 & 0.0179 & 0.0074 \\
\hline Pool & 0.0363 & 0.0368 & 0.0435 & 0.0499 & 0.0518 \\
\hline Age Sq & 0.0000 & 0.0000 & 0.0000 & 0.0000 & 0.0000 \\
\hline Acres Sq & -0.1572 & -0.1988 & -0.1138 & -0.0893 & -0.2120 \\
\hline Square Feet Sq & -0.0004 & -0.0004 & -0.0004 & -0.0003 & -0.0003 \\
\hline Monthly Trend & 0.0061 & 0.0000 & 0.0043 & 0.0228 & -0.0059 \\
\hline \# Observations & 114,143 & 62,779 & 107,556 & 283,888 & 51,128 \\
\hline Adjusted $\mathrm{R}^{2}$ & 0.9998 & 0.9995 & 0.9997 & 0.9997 & 0.9998 \\
\hline
\end{tabular}

${ }^{1}$ Bold indicates $90 \%$ significance. 
Table 4: Fixed Effect Decomposition ( $N=15,739)$

\begin{tabular}{|c|c|c|c|c|c|c|c|c|c|c|c|c|c|c|c|}
\hline \multirow[b]{3}{*}{ Variable } & \multicolumn{12}{|c|}{ Model Specification } & \multirow{2}{*}{\multicolumn{3}{|c|}{ E: Inverse Distance }} \\
\hline & \multicolumn{3}{|c|}{ A: No Interactions } & \multicolumn{3}{|c|}{ B: Directional Spillovers } & \multicolumn{3}{|c|}{ C: Connector Spillovers } & \multicolumn{3}{|c|}{ D: Full Spillovers } & & & \\
\hline & Estimate & Std Err & t-Stat & Estimate & Std Err & t-Stat & Estimate & Std Err & t-Stat & Estimate & Std Err & t-Stat & Estimate & Std Err & t-Stat \\
\hline Price Dummy & 0.0372 & 0.01 & 3.7900 & 0.1008 & 0.03 & 3.3700 & 0.0872 & 0.02 & 5.7900 & 0.1006 & 0.03 & 3.3700 & 0.0229 & 0.0066 & 3.4598 \\
\hline Pima Dummy & 0.2359 & 0.01 & 31.4100 & 0.2361 & 0.01 & 31.4500 & 0.2375 & 0.01 & 31.6100 & 0.2378 & 0.01 & 31.6400 & 0.0995 & 0.0056 & 17.6222 \\
\hline Connector Dummy & 0.1346 & 0.02 & 8.9400 & 0.1428 & 0.02 & 8.9600 & 0.1589 & 0.02 & 9.6300 & 0.1634 & 0.02 & 9.7700 & 0.0521 & 0.0118 & 4.4104 \\
\hline Santan Dummy & 0.0729 & 0.01 & 5.1400 & 0.0752 & 0.01 & 5.2000 & 0.0757 & 0.01 & 5.2400 & 0.0743 & 0.01 & 5.1300 & 0.016 & 0.0066 & 2.4187 \\
\hline Adjacent Price & 0.0087 & 0.03 & 0.3300 & 0.0091 & 0.03 & 0.3400 & 0.0121 & 0.03 & 0.4600 & 0.0120 & 0.03 & 0.4600 & -0.047 & 0.0375 & -1.2519 \\
\hline Adjacent Pima & -0.0322 & 0.02 & -1.6400 & -0.0325 & 0.02 & -1.6500 & -0.0326 & 0.02 & -1.6500 & -0.0331 & 0.02 & -1.6800 & -0.2785 & 0.0316 & -8.8272 \\
\hline Adjacent Connector & -0.0061 & 0.05 & -0.1300 & -0.0035 & 0.05 & -0.0700 & -0.0050 & 0.05 & -0.1100 & -0.0050 & 0.05 & -0.1100 & -0.0895 & 0.0656 & -1.3647 \\
\hline Adjacent Santan & 0.0085 & 0.02 & 0.4600 & 0.0077 & 0.02 & 0.4100 & 0.0086 & 0.02 & 0.4600 & 0.0091 & 0.02 & 0.4900 & 0.0104 & 0.0214 & 0.4832 \\
\hline Phoenix CBD & 0.0026 & 0.00 & 8.3500 & 0.0026 & 0.00 & 8.3700 & 0.0026 & 0.00 & 8.4700 & 0.0026 & 0.00 & 8.4900 & 0.0021 & 0.0003 & 6.8584 \\
\hline Constant & 10.2328 & 0.02 & 446.7800 & 10.2328 & 0.02 & 446.8100 & 10.2323 & 0.02 & 446.9800 & 10.2319 & 0.02 & 446.9600 & 10.234 & 0.0234 & 436.6595 \\
\hline Price/Pima ${ }^{\mathrm{b}}$ & & & & -0.0706 & 0.03 & -2.2500 & & & & -0.0179 & 0.03 & -0.5200 & & & \\
\hline Price/Connector Dummy & & & & & & & -0.0844 & 0.02 & -4.3600 & -0.0876 & 0.02 & -4.0300 & & & \\
\hline Price/Santan & & & & & & & & & & 0.0600 & 0.04 & 1.6200 & & & \\
\hline Connector/Santan & & & & -0.0306 & 0.04 & -0.7800 & -0.0287 & 0.04 & -0.7300 & -0.0665 & 0.05 & -1.4600 & & & \\
\hline
\end{tabular}


Table 5. Benefit/Cost of Highway Segments

\begin{tabular}{|c|c|c|c|c|c|c|c|c|c|c|c|c|c|c|}
\hline \multirow[b]{2}{*}{ House Population } & \multicolumn{2}{|c|}{ Proximity Measure } & \multicolumn{2}{|c|}{ Adjacent Prices $^{\mathrm{a}}$} & \multicolumn{2}{|c|}{ Near Prices ${ }^{\mathrm{b}}$} & \multicolumn{4}{|c|}{ Value of Segment } & \multirow{2}{*}{$\begin{array}{r}\text { Cost of } \\
\text { Segment }\end{array}$} & \multirow{2}{*}{$\begin{array}{r}\text { Length } \\
(\mathrm{mi})\end{array}$} & \multirow{2}{*}{$\begin{array}{r}\text { Benefit/Mile } \\
\text { Model D }\end{array}$} & \multirow{2}{*}{$\begin{array}{r}\text { Cost / } \\
\text { Mile }\end{array}$} \\
\hline & Adjacent & Near & \# Sales & Avg Price & \#Sales & Avg Price & A & B & $\mathrm{C}$ & $\mathrm{D}$ & & & & \\
\hline Price Freeway & 5,015 & 76,032 & 1,122 & 206,573 & 21,090 & 216,947 & $622,979,481$ & $506,515,766$ & $58,252,701$ & $921,150,516$ & $175,000,000$ & 12.5 & $73,692,041$ & $14,000,000$ \\
\hline Pima Freeway & 7,052 & 116,220 & 2,449 & 235,562 & 33,064 & 299,323 & $8,152,247,595$ & $8,159,489,361$ & $8,208,565,305$ & $8,217,003,271$ & $380,000,000$ & 30 & $273,900,109$ & $12,666,667$ \\
\hline Connector Freeway & 1,360 & 41,341 & 348 & 248,711 & 7,925 & 278,058 & $1,545,472,747$ & $1,288,324,459$ & $1,496,027,161$ & $1,111,862,080$ & $120,000,000$ & 5 & $222,372,416$ & $24,000,000$ \\
\hline Santan Freeway & 7,079 & 120,133 & 758 & 312,157 & 6,270 & 343,098 & $3,024,043,464$ & $3,116,352,541$ & $3,138,638,564$ & $3,082,424,019$ & $425,000,000$ & 20.2 & $152,595,248$ & $21,039,604$ \\
\hline
\end{tabular}

${ }^{b}$ Averaged over houses selling after freeway opening within 3 miles of the specified freeway, including adjacent houses 


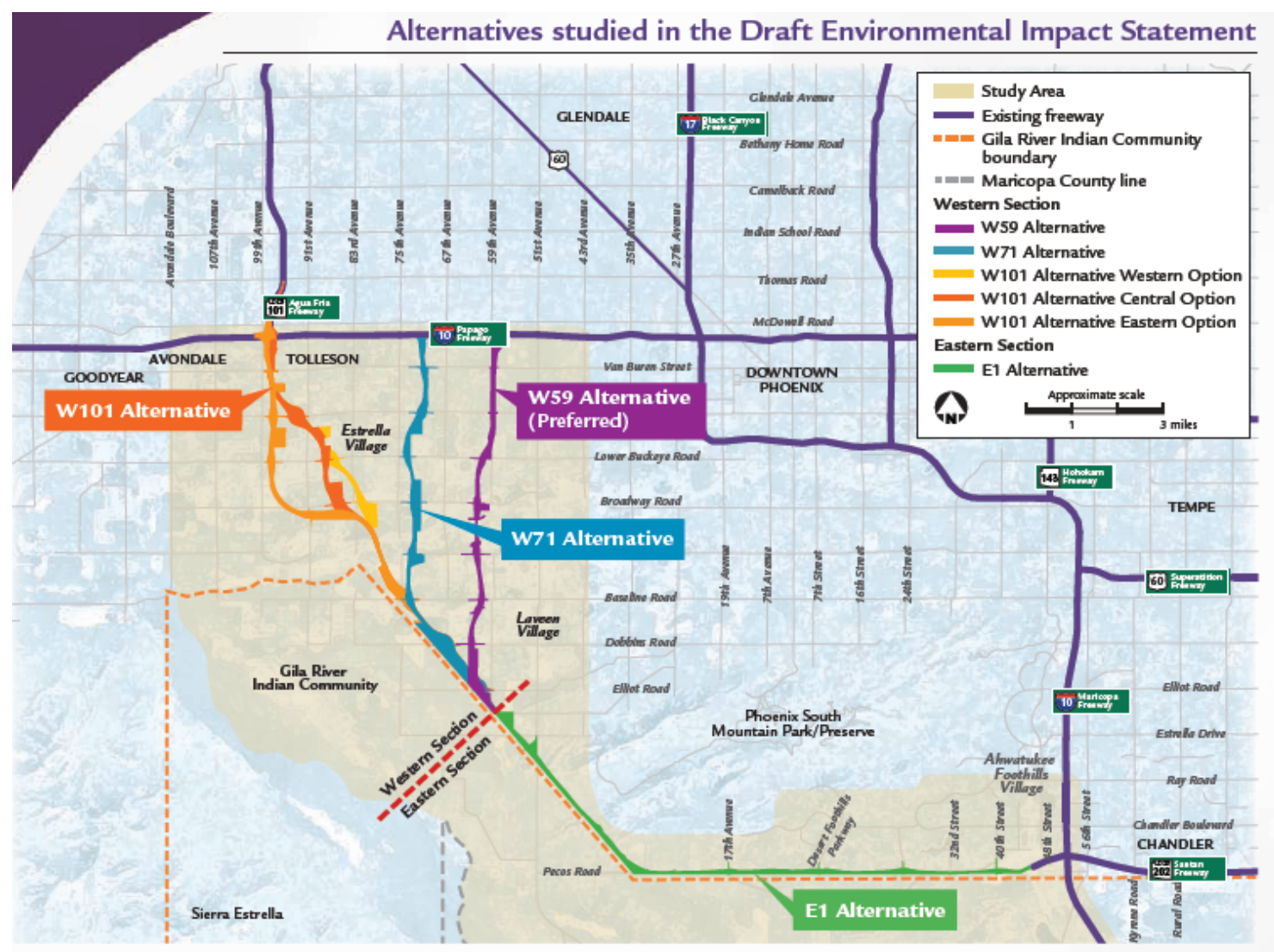

Figure1. Alternatives Studied in the Draft Environment Impact Statement; South Mountain 


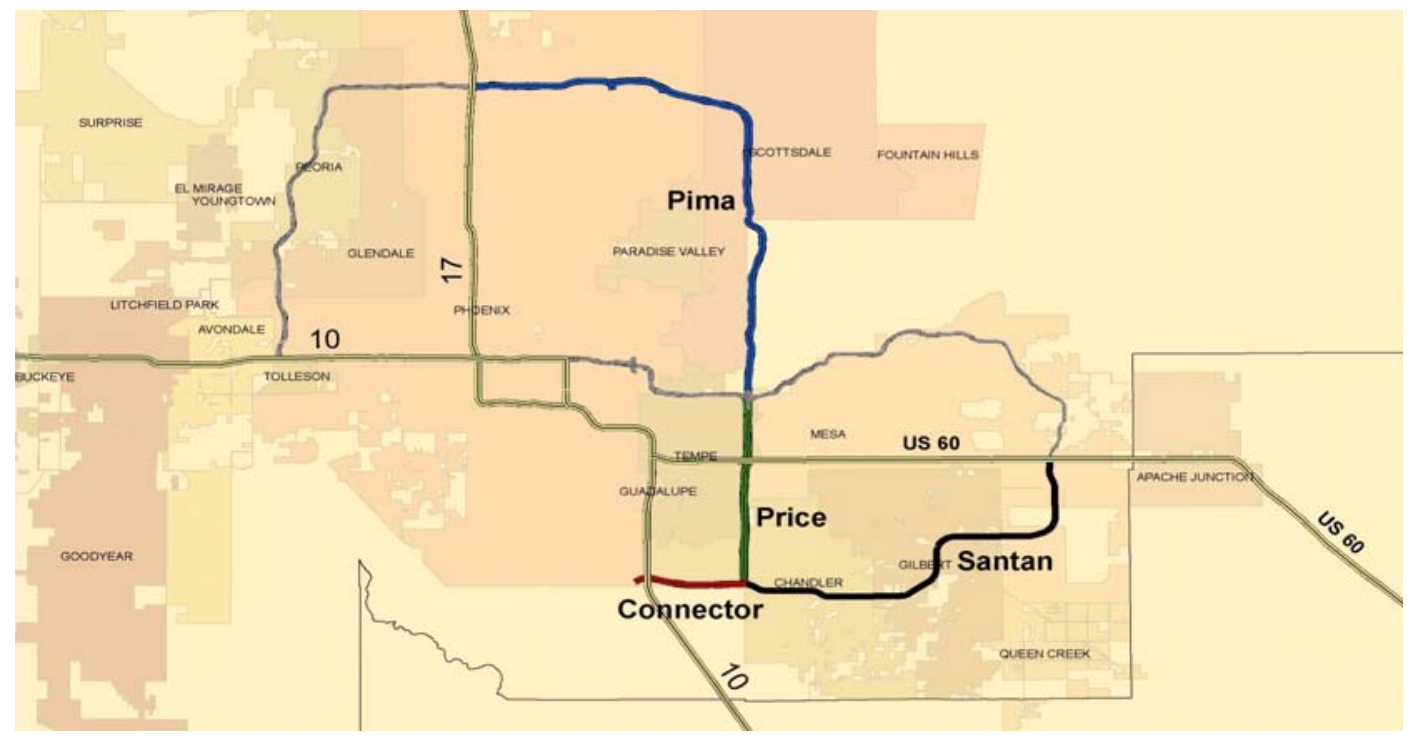

Figure 2. Key Highway Segments 


\section{Price Freeway}

Time 2

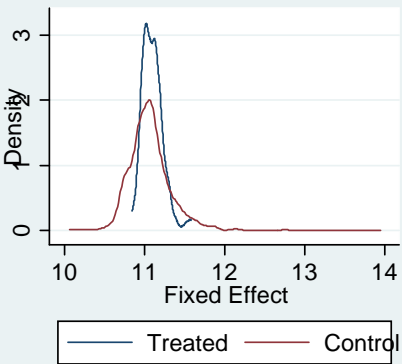

Time 5

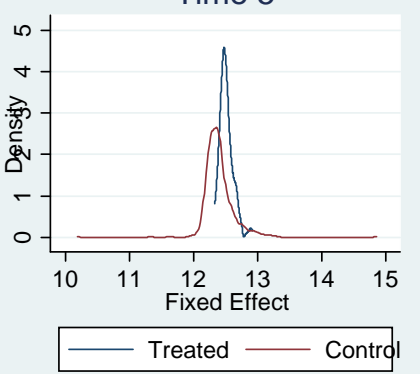

Time 3
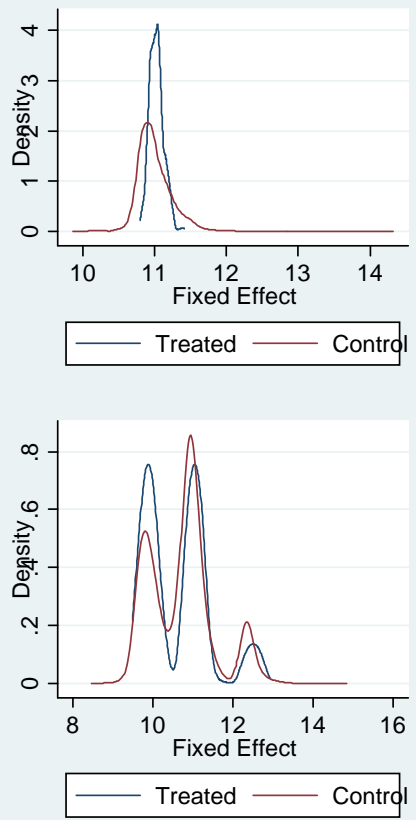

Time 4

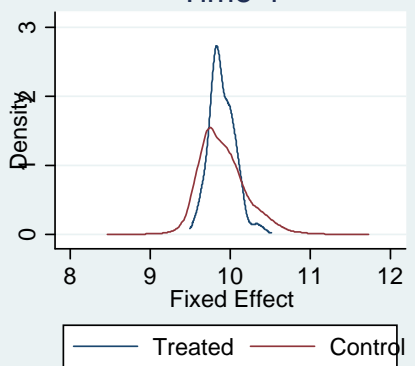

Figure 3. Price Segment; Estimated Density 


\section{Pima Freeway}

Time 3

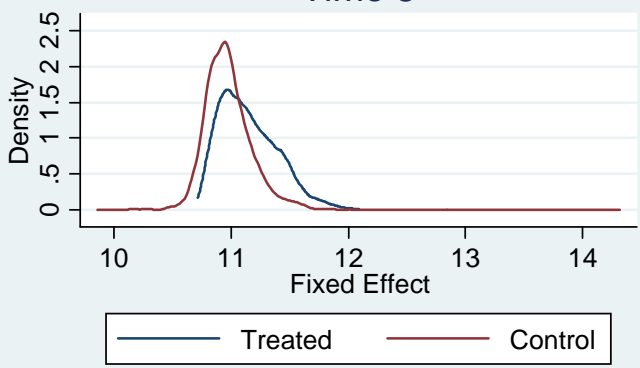

Time 5

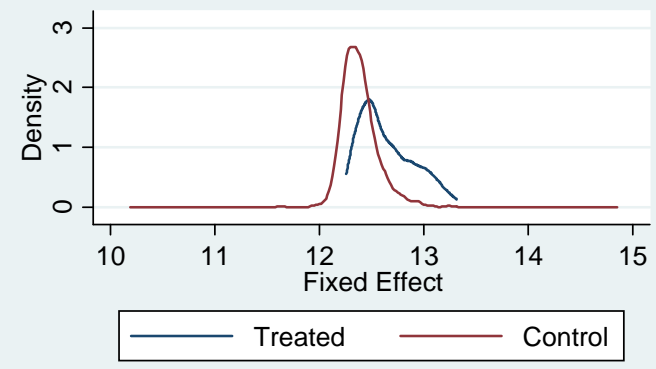

Time 4

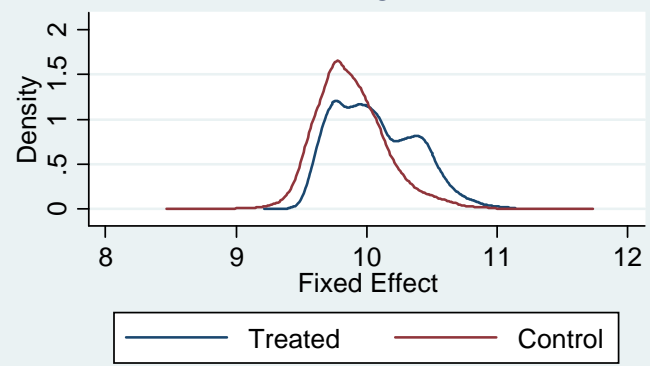

Time Full

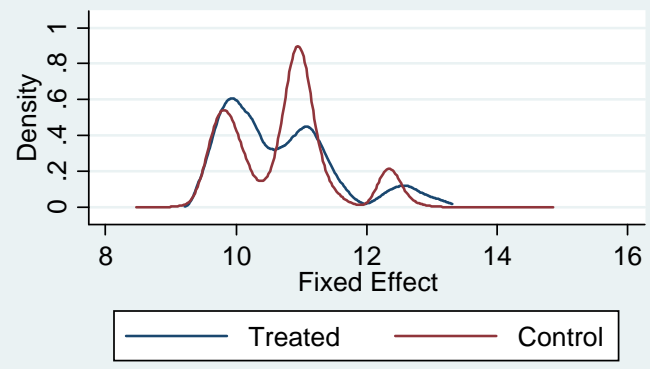

Figure 4. Pima Segment; Estimated Density 


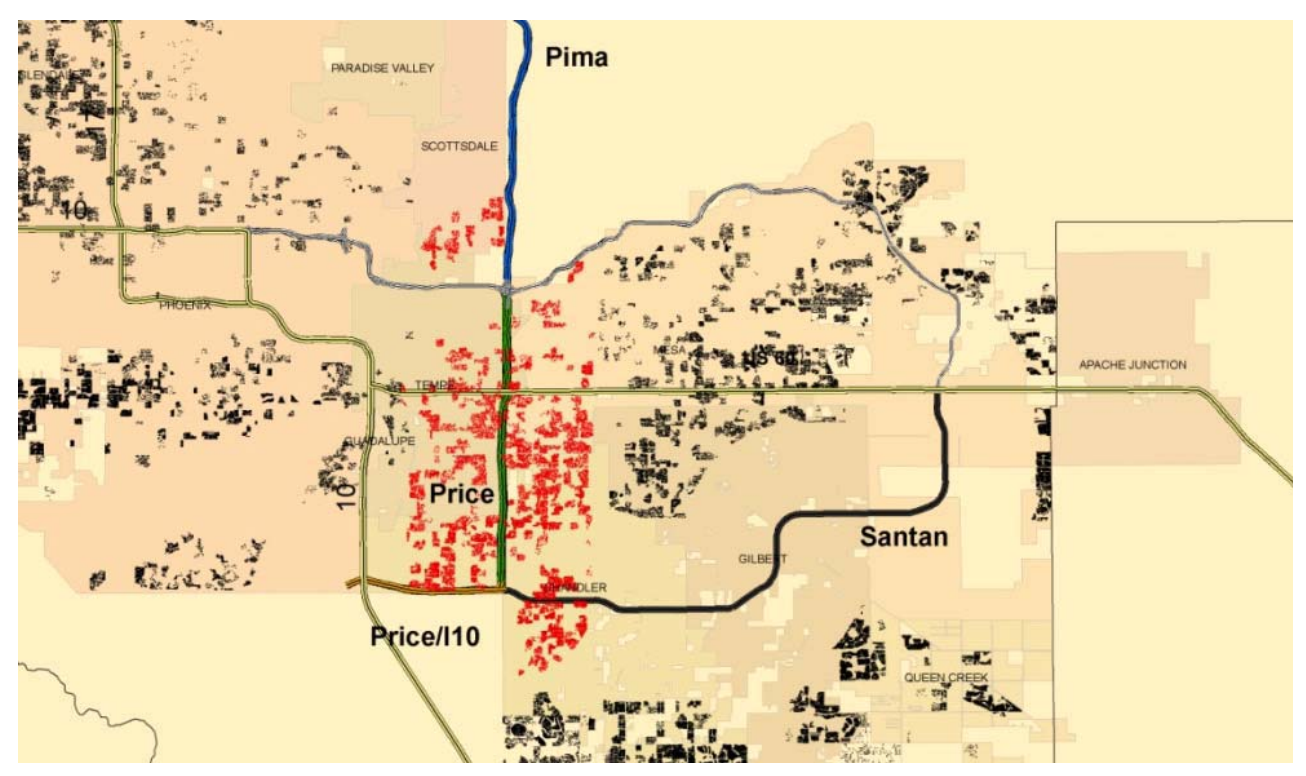

(a) Price Freeway Subdivisions

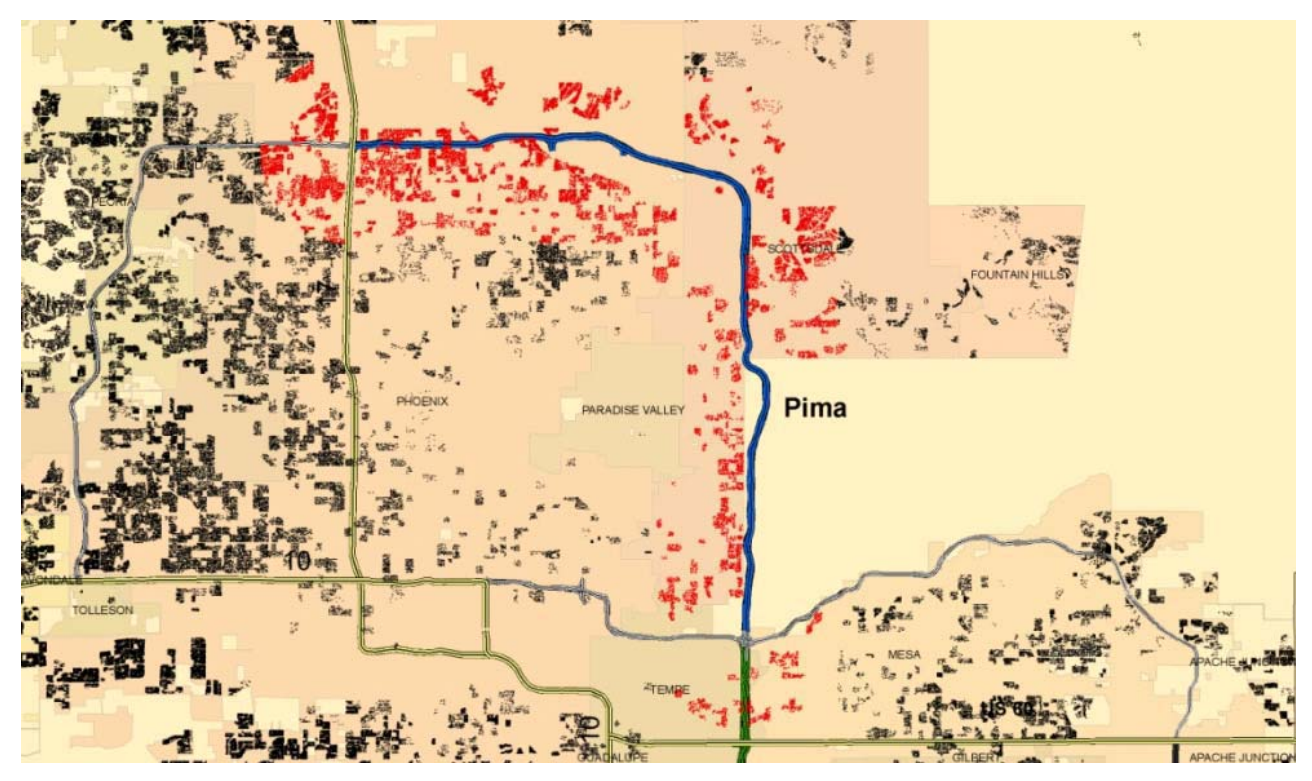

(b) Pima Freeway Subdivisions

Figure 5: Housing transactions in Subdivisions used during analysis 


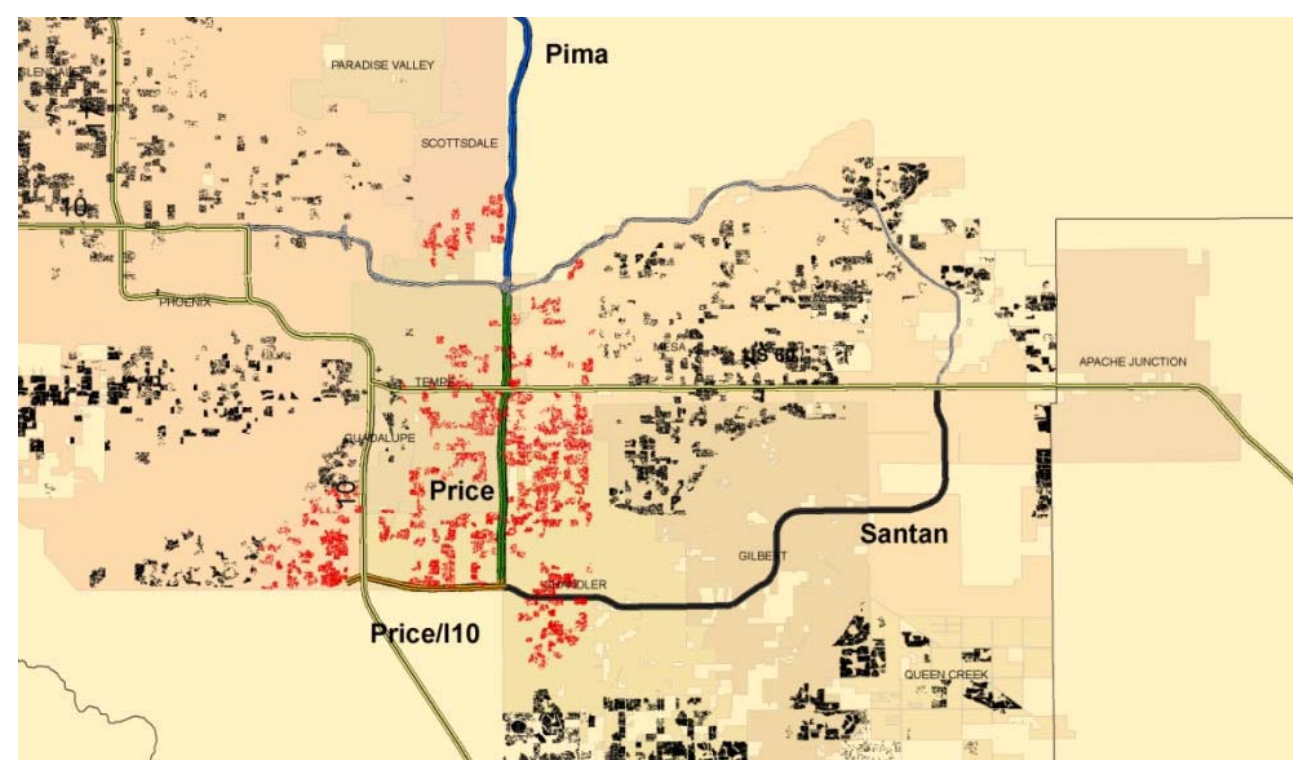

(c) Connector Subdivisions

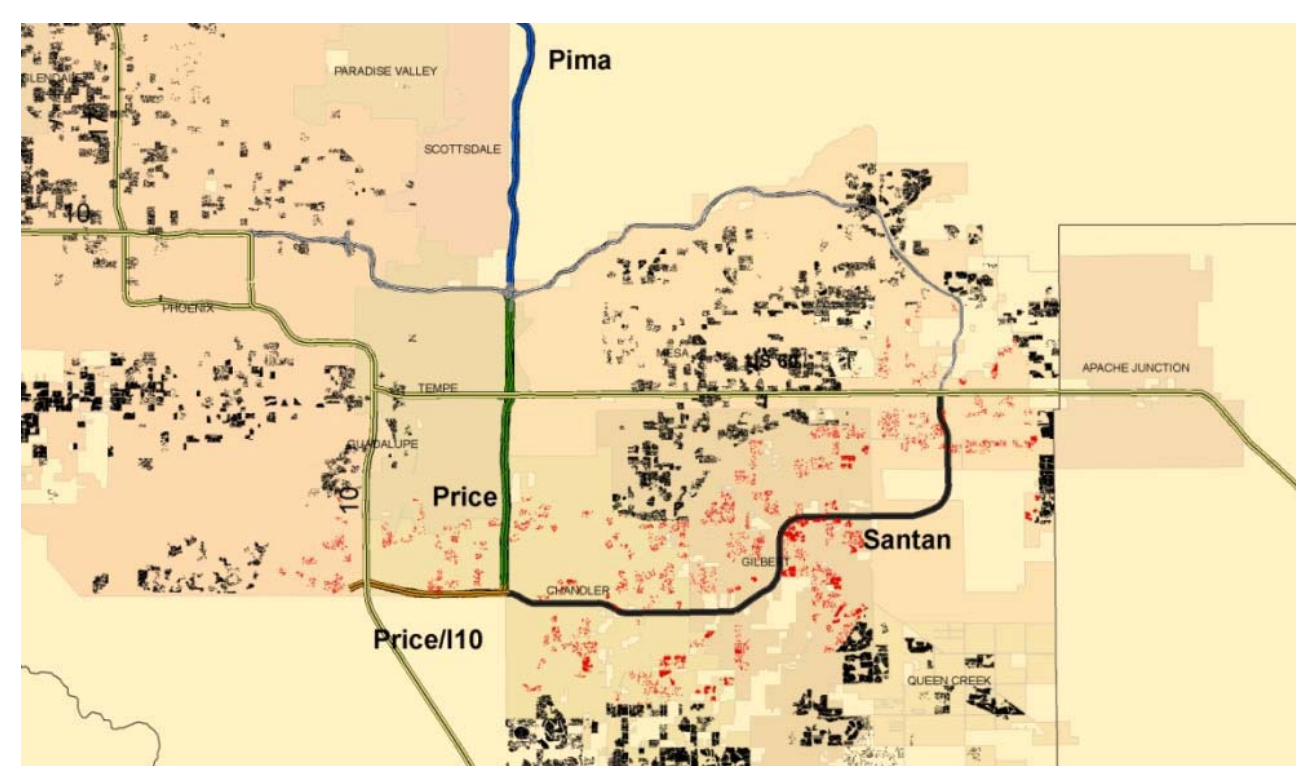

(d) Santan Freeway Subdivisions

Figure 5: continued 